ORIGINAL PROF-2085

\title{
DENGUE OUTBREAK;
}

Descriptive epidemiological analysis and vector surveillance in District Faisalabad during 2011.

Dr. Muhammad Asif Shahzad, Dr. Abdul Rauf, Dr. Humayun Suqrat Hasan Imam, Miss Rameesha Humayun

ABSTRACT... Background: This longitudinal study was conducted during August to December 2011 in District Faisalabad to analyze epidemiological pattern of dengue outbreak in the district. Weekly trends of all cases (893) reported through Disease Surveillance System from week No.33 to 54 were monitored. On the basis of this continuous flow of information, different ongoing vector control measures were adopted simultaneously in different areas of the district and larval indices were calculated. Methods: The Surveillance data was used to monitor the trends of the outbreak in terms of time, person and place. Teams of 3102 trained workers were formed to conduct various surveillance activities like vector surveillance, fogging, larviciding, and indoor residual sprays. During indoor and outdoor vector surveillance, teams also calculated the larval indices for vector control. Results: The rural to urban ratio of cases was 1:3. Maximum cases (215) were reported from Jinnah Town in urban area and (102) cases were reported from Tehsil Sadar among the rural areas. Most cases of dengue fever were observed during the $40-45$ weeks of the year 2011. Mean age was $29 \pm 14.7$ years for rural and $35 \pm 16.5$ years for urban. Male to Female ratio was 1.2:1 in urban and 1.8:1 in rural areas. Majority of the cases belonged to the age group 21-30. The case fatality rate was $6 / 1000$ cases. The house Index was $1.03 \%$, the indoor container index was $0.26 \%$ and the breateu index was found $1.21 \%$. Conclusions: Maximum cases occurred during 44th and 45th weeks. Male were affected more as compare to females. Jinnah Town in urban areas and Tehsil Sadar among the rural areas reported maximum number of cases. The different calculated larval indices like house index, indoor/outdoor container index and breateu index showed moderate larval growth and hence, the outbreak was within control.

Key words: Surveillance, Urban/Rural Distribution, Male/Female ratio, weekly trend.

\section{Article Citation}

$\checkmark \quad$ Shahzad MA, Rauf A, Imam HSH, Humayun R. Descriptive epidemiological analysis of dengue outbreak and vector surveillance in District Faisalabad during 2011. Professional Med J Feb 2013;20(1): 045-053.

\section{INTRODUCTION}

District Faisalabad comprises of 6 Tehsils / 8 Towns having boundaries with Districts Chiniot, Hafizabad, Nankana Sahib, Okara, Sahiwal and TT Singh. It has 289 Union Councils. The demographic picture is as under:

The population of District Faisalabad is 6542641 (2011). It has two teaching hospitals and five THQ Hospitals. Rural Health Centers are twelve and 263 Health Facilities including Basic Health Units, Zila Council and Government dispensaries.

After the catastrophic effect of dengue epidemic in Lahore during 2011 in which 17531 cases were reported with 301 deaths, it was imperative to look into epidemiological trends of this disease in the second largest city of Punjab i.e. Faisalabad. The dengue infection was first documented in Pakistan in1982

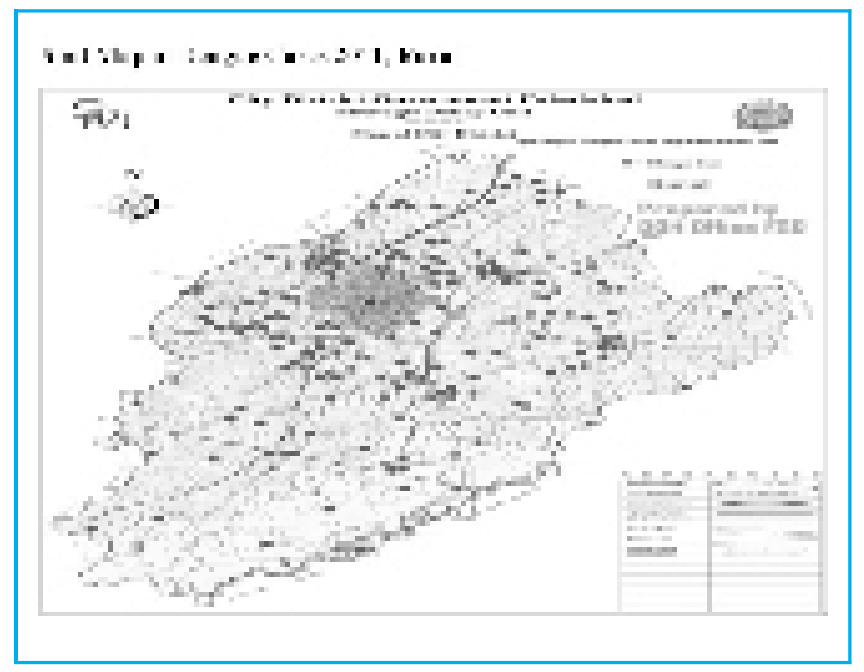

from Punjab province in 12 patients out of $174^{1}$. The first major epidemic of dengue fever was reported in Karachi in 1994-1995 ${ }^{1}$. It is highly important to increase our knowledge of present climate, heath relationship, particularly seasonality of disease since 


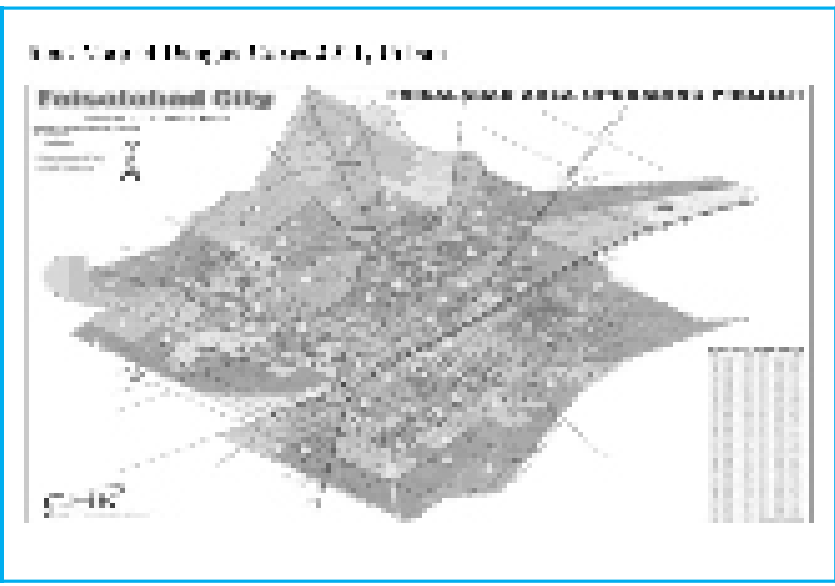

this will help in focusing our efforts towards limiting factors of the disease ${ }^{2}$, which is the purpose of this study. In our study, there is a rise in the number of cases from 37 to 46 weeks, which was the most rainy and humid season of the year. According to World Health Organization, more than 2.5 million people are at risk of developing dengue fever ${ }^{1}$. Dengue is the most important mosquito-borne, human viral disease in many tropical and sub-tropical areas. In India, the disease has been essentially described in the form of case series ${ }^{3}$. Changes in adult mosquitoes were monitored with BG-Sentinel traps and oviposition activity with communicable disease control enhanced ovitraps ${ }^{4}$. There has been a 30 -fold increase in the number of dengue cases over the past 50 years 5 . Recent studies estimate 50-100 million infections each year, ${ }^{6}$ although, owing to under-reporting, this figure could be even higher ${ }^{7}$.

The burden of dengue currently falls most heavily on Southeast Asia, but dengue has spread throughout Latin America and more than half of the world's population now lives in dengue-endemic countries ${ }^{5}$. Moreover, increasing numbers of travelers return from endemic regions with dengue, is further increasing its spread, and leading to cases of locally acquired dengue in the USA ${ }^{8}$ and Europe ${ }^{9}$. Climate conditions in the Middle East are not favorable for the disease vector, but all other risk factors for dengue are potentially increasing $^{10}$. The results of case study conducted in
Saudi Arabia demonstrated that it would be useful to follow the monthly DF pattern, based on the average weekly frequency. This will be helpful for resource allocation $^{11}$. Given the epidemic potential of dengue virus in Mayotte, adequate monitoring including early detection of cases, timely investigation and sustained mosquito control actions remain essential ${ }^{12}$. Periodic outbreak patterns are also highly influenced by seasonal climatic conditions. Thus, these factors are important considerations when assessing the effect of vector control against dengue ${ }^{13-14}$. Vector-borne diseases impose enormous health and economic burdens and additional methods to control vector populations are clearly needed ${ }^{15}$. Increased air travel and the breakdown of vector control measures have also contributed greatly to the global burden of dengue and $\mathrm{DH}$ fevers ${ }^{16}$. Rural areas may contribute at least as much to the dissemination of dengue fever as cities. Improving water supply and vector control in areas with a human population density critical for dengue transmission could increase the efficiency of control efforts ${ }^{17}$. In many countries in Asia and South-America dengue fever (DF) and dengue hemorrhagic fever (DHF) has become a substantial public health concern leading to serious socio-economic costs ${ }^{18}$. Demographic, economic, behavioral and social factors are often keys for effective communicable disease control and underpin successful public health programmes $^{19}$. Historically, DF/DHF has been reported as occurring predominantly among urban populations where density of dwellings and short flying distance of the vector create the right conditions for transmission ${ }^{19}$.

\section{Objectives}

To analyze the Epidemiological Trends in District Faisalabad

To assess different larval indices for controlling dengue outbreak during this period 


\section{METHODOLOGY}

\section{Data collection procedures and surveillance} activities

All cases (471) with addresses out of District Faisalabad were excluded. Data was collected from the surveillance cell for dengue fever in the office of EDO Health, Faisalabad. In the light of data collected, the trend of spread of dengue in term of time, place and person was monitored. The teams of 3102 trained persons were constituted to help out in measuring the larval indices like House Index etc as well as Indoor and Outdoor Vector Surveillance activities, Indoor Residual Spray, Larviciding and Fogging activities. These activities were more focused on the areas affected badly by the outbreak. During Indoor Vector Surveillance our teams checked 149816 houses and 1550 houses were found positive for aedes larvae, so the House Index was 1.03\%. During the same activity, the teams found 690103 containers, out of them 1814 containers were found positive, thereby the Container Index (Indoor) was found $0.26 \%$ and the Breateu Index was found 1.21\%. During Outdoor Vector Surveillance, our teams checked 15970 spots in which they found 26836 containers, out of those 488 containers were found positive, thereby Container Index (Outdoor) was found $1.81 \%$.

\section{Data analysis procedures}

Quality of the data was maintained. Excel 2007 was used to evaluate the results in the form of spot maps and graphs. Descriptive statistics were expressed in the form of mean, mode, median and standard deviation. Larval indices like house index, breateu index, container index, were calculated by using appropriate formulae. Case fatality rate was also calculated at the end of the 52nd week.

\section{RESULTS}

Reporting started from week \# 33 (Aug 15-21, 2011). The age of the cases ranged from 1-95 years in urban and 1-70 years in rural areas. Ages of 3 cases (urban) were unknown. The cumulative incidence rate of dengue was 136/1000000/year. The rural to urban ratio of cases was 1:3. Maximum cases (215) were reported from Jinnah Town in urban area and (102) cases were reported from Tehsil Sadar among the rural areas. Mean age was $29 \pm 14.7$ years for rural and $35 \pm 16.5$ years for urban. Male to Female ratio was 1.2:1 in urban and 1.8:1 in rural Areas. Majority of the cases belonged to the age group 21-30 years in both urban (192) and rural (64) while there was another spike (137 cases) in the age group of 41-50 years in urban area. Deaths of five patients were reported. Out of these deaths four were females (age $13,45,60$ and 65 years) and one male (age 24 years) The case fatality rate was $6 / 1000$ cases. The House Index was $1.03 \%$ and the Breateu Index was found $1.21 \%$. The Indoor and Outdoor Container Index was found $0.26 \%$ and $1.81 \%$ respectively.

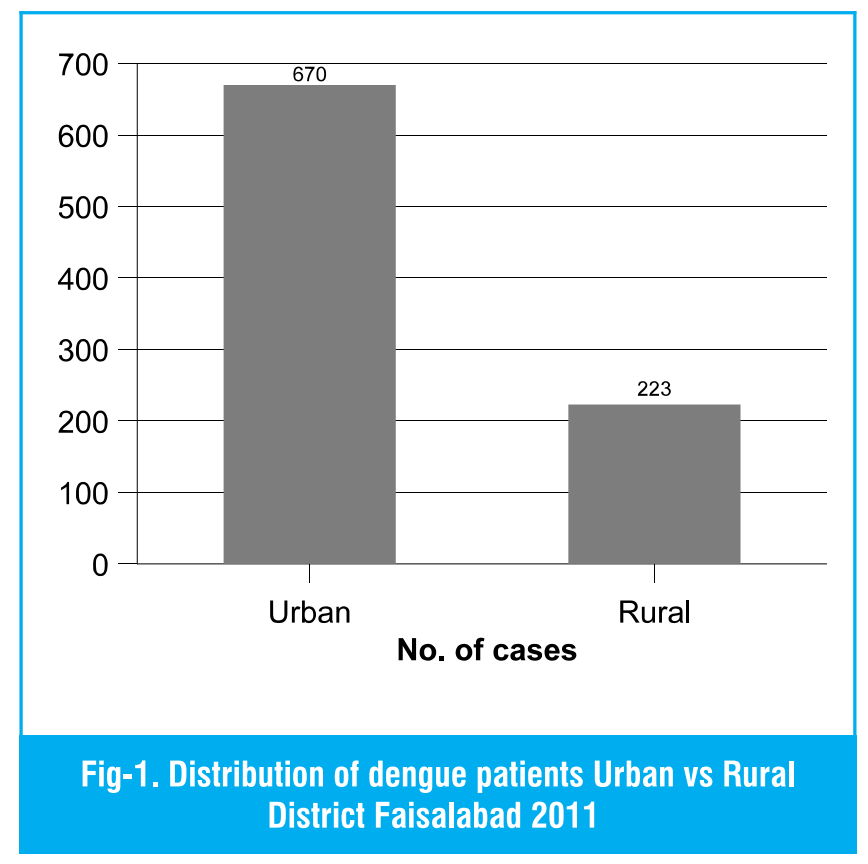

Out of total cases of District Faisalabad admitted in Allied and DHQ Hospital, 670 belong to urban area and 223 related to rural settings. In urban area dengue fever was three times more common as compared to rural area.

Fig 2 and 3 depicts male and female patterns of dengue 

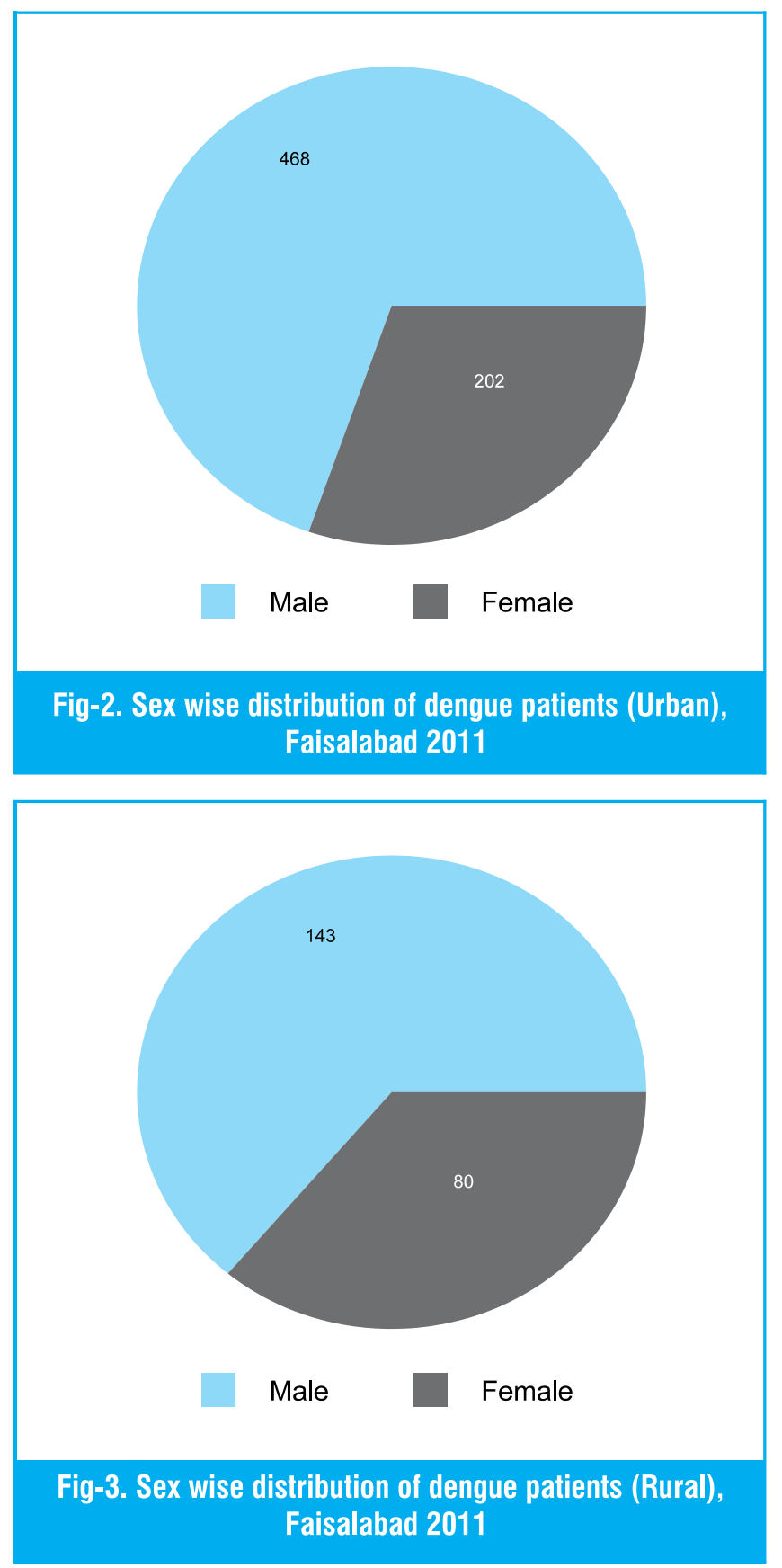

fever in urban and rural settings. This pattern is similar in both areas where males are twice affected by this disease as compared to their counterparts.

Jinnah town and Lyallpur town have more concentration of dengue patients as compared to other towns of urban Faisalabad.
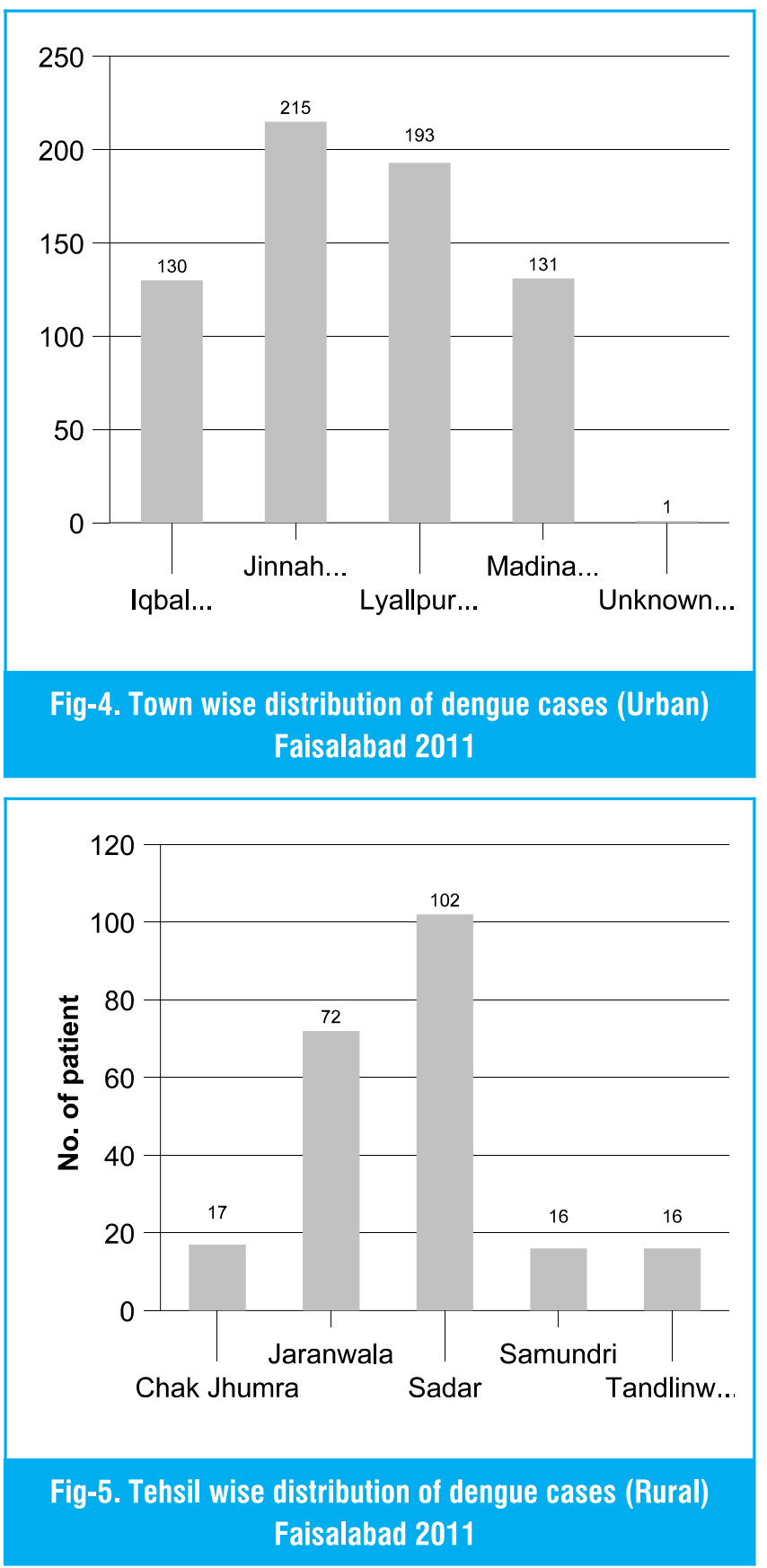

Tehsil Sadar and Jaranwala have more concentration of cases as compared to other three Tehsils.

Most cases of dengue fever were observed during the 40-45 weeks of the year 2011. Highest peak was observed during the 44th week of this year. 

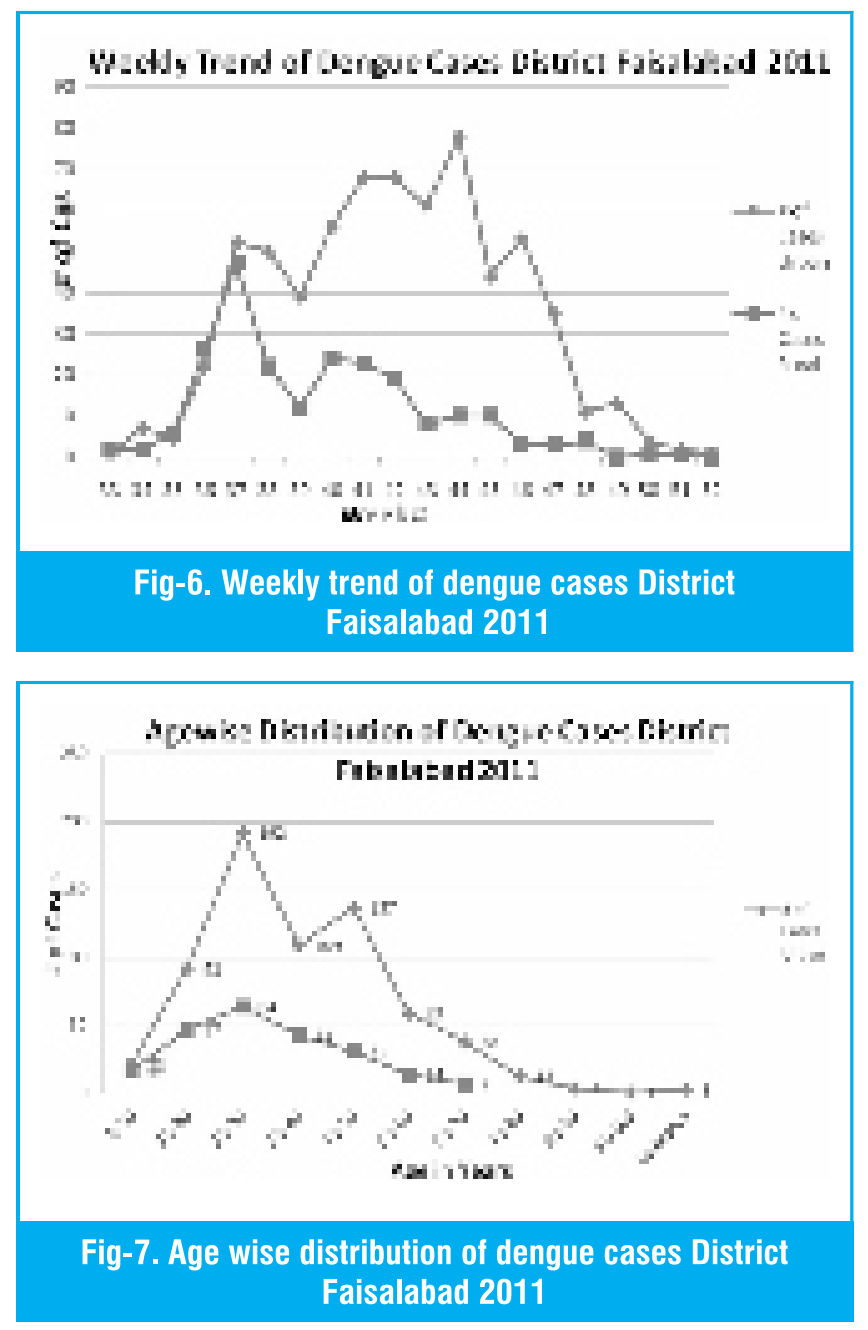

Most cases in urban and rural settings were found among age group of 21-30 years. This trend declined with the increase in age. Second peak was observed in age group of 41-50 years. This trend relates to the working group of population.

\section{DISCUSSION}

The study in Eastern Sudan showed mean age of 81 patients was 25.5 years and male: female ratio was $1.8: 1^{20}$. A study was conducted in Cuba regarding the intervention which encompasses two main stages separated by two dengue outbreaks. The first stage, focused on strengthening intersectoral coordination, was initiated in January 2000. In August 2003, a complementary strategy, focused on community

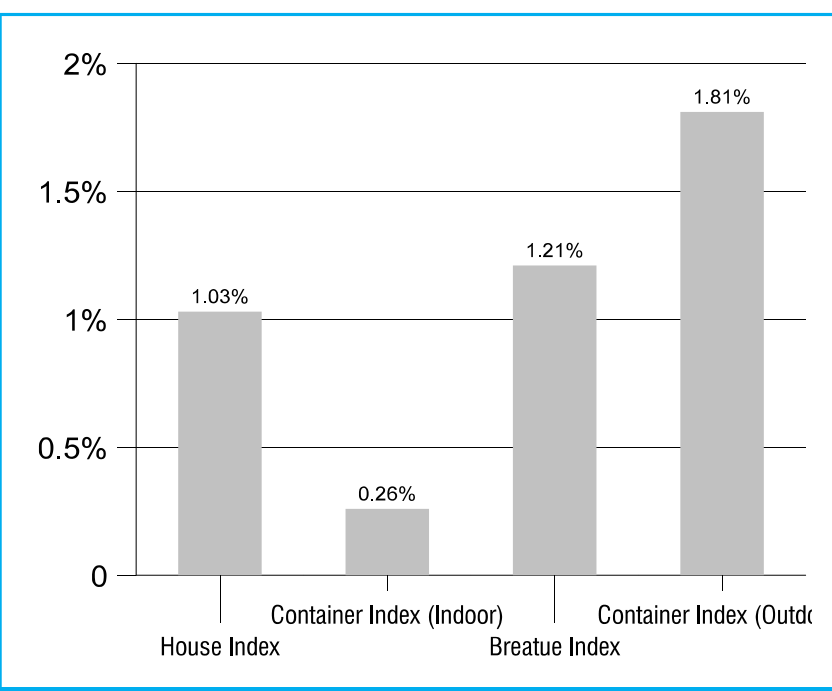

Fig-8. Larval indices of Faisalabad District 2011

empowerment and was initiated in half of the intervention area $^{21}$. Dengue infection is widespread across Bangladesh, but malaria is sufficiently uncommon that it should not be assumed as the cause of fever without laboratory confirmation ${ }^{22}$. In Mexico the adult density index (ADI) and traps positive index (TPI) were calculated, and data were used to obtain the monthly dengue dispersion maps. The highest abundance of female (137 and 139) was found in July and August. In August and September the sectors 2, 4 and 6 showed the highest ADI values 2.44, 3.35 and 2.290, while TPI values were $56.25,58.82$ and 61.54 , with the highest epidemiology dengue dispersion ${ }^{23}$. In a study conducted in Karachi the most of the cases were found during the month of September and throughout November ${ }^{2}$. In our study the pattern of spread of dengue in urban and rural area of Faisalabad was fund most abundant during the months of August to November. This period is related to rainfall and humidity. Another study also confirmed that the majority of cases $75.3 \%$ occurred in the period of June 2006-October 2006, which is consistent with the occurrence of this disease during summer and monsoon season in Pakistan ${ }^{24}$. In Malaysia larvae population was assessed with ovitraps, which were placed outdoor and used to determine the effects of meteorological parameters on vector breeding ${ }^{25}$. In our 
study we used the different larval indices to monitor the vector growth and adequate preventive measures were adopted accordingly. In Malaysian study vector population in each area was monitored weekly for 87 weeks. Weather stations, consisting of a temperature and relative humidity data logger and an automated rain gauge, were installed at key locations in each study site ${ }^{25}$. Previous week rainfall plays a significant role in increasing the mosquito population, followed by maximum humidity and temperature ${ }^{25}$. Three independent studies from epidemics in India and Singapore found nearly twice the number of male patients compared to females (Lucknow and Singapore both report male to female ratios of 1.9:1 and Delhi 1:0.57 $)^{26-28}$. In a hospital-based study during the 1996 epidemic in Delhi, Wali reported an even higher ratio of $2.5: 1^{29}$. Surveillance data from Malaysia revealed a male preponderance among Indian and Malay patients (1.5:1), but the ratio was almost equal for those of Chinese origin ${ }^{30}$. A study conducted in a hospital of Rawalpindi showed male to female ratio of 2.4:1 in study population ${ }^{31}$.

In the present study the male to female ratio in urban and rural setting is 2:1. Today, Thailand has an incidence rate that is higher in rural (102.2 per $100,000)$ than urban areas $(95.4 \text { per } 100,000)^{32}$. Similarly, in India, entomological investigation showed a widespread distribution of Aedes aegypti, both in rural and urban areas during an outbreak in Gujarat in 1988 and $1989^{33}$. The incidence and, in particular, epidemics of dengue have been commonly associated with the rainy season, and the El Niño phenomenon has been incriminated in the increases of certain vector-borne diseases, including dengu ${ }^{34,35}$. As indicated in our study and suggested by another study that large set of data is needed to underscore the epidemic and endemic pattern of dengue in different provinces of Pakistan ${ }^{36}$. The pan American Health Organization described three levels of risk for dengue transmission: low (House Index $(\mathrm{HI})<0.1 \%$ ), medium $(\mathrm{HI} 0.5 \%-1 \%)$, high $(\mathrm{HI}>5 \%)^{37}$. However, dengue outbreaks occurred in Singapore when the national overall HI was $<1 \%$. In contrast, researchers from Fortaleza, Brazil, found that dengue outbreaks never occurred when $\mathrm{HI}$ was $<1 \%$. The above mentioned study was done in $\mathrm{Cuba}^{37}$. As continuation of present study, in November 2011, indoor and outdoor surveillance for detection of aedes larvae was conducted in District Faisalabad, which showed that container index for outdoor was 3.4. The container index for indoor was 0.98 , house index was 2.51 and breateu index was 2.56. These calculated indices in Faisalabad showed that level of risk of transmission of dengue in the community was medium and better preventive strategy and change in weather averted a potential threat of severe epidemic.

\section{CONCLUSIONS}

Prevalence of disease was more common in urban setting than the rural ones and most of the cases were found in urban and suburban areas. The males were affected more as compared to the females but mortality rate was higher among females than males (4 to 1). Most cases were noticed during 37th to 46th week of the year 2011. Case fatality rate was $6 / 1000$ cases. The calculated house index (1.03\%) and breateu index $(1.21 \%)$ established the moderate transmission of disease vector. This study will help to fill the gap in the public health intervention for future epidemic and its control in the District Faisalabad.

\section{ACKNOWLEDGMENT}

We are at a loss of words to give vent to our feelings of thankfulness to Almighty, Allah, who despite of our entire tight schedule of our day to day assignments, to complete this article, successfully. We are proud of being the humble members of the Anti- Dengue Project/ Surveillance Team of District Faisalabad. We wish to express our gratitude to those who generously helped us in coloring the mosaic of this article. We are also grateful to the both focal persons Dr Khurrum Altaf Shami and Dr Muhammad Khalid Bhatti, the focal persons of Allied and DHQ Hospitals respectively for 
providing us the accurate and valuable information about each case, day by day till the end of the outbreak.

We would like to pay special thanks to Miss Raashida Nasreen Assistant Entomologist, Mr. Ehsan Ullah Zaheer Statistical Officer, Mr. Kashif Latif, Mr Aamir Tanveer, and Mr Sana Ullah Computer Operators for timely preparing, updating and disseminating of the line lists of the Dengue cases and other information on daily basis.

Copyright@ 22 Nov, 2012.

\section{REFERENCES}

1. Nagi AG, Murad R, Baig M. Dengue fever outbreak among children in Karachi: experience at a tertiary at a care children hospital. JBUMDC 2011; 1 (2): 44-8.

2. Qadar M, Murad R, , Aziz N, Azmi A, Khan TMA. Pattern of dengue fever in different weather conditions of Karachi. Jul-Sep 2011;20 (3)): 331-2.

3. Chakravarti A, Arora R, Luxemburger C. Fifty years of dengue in India. Trans R Soc Trop Med Hyg. 2012 Feb 20.

4. Barrera R, Amador M, MacKay AJ. Population dynamics of Aedes aegypti and dengue as influenced by weather and human behavior in San Juan, Puerto Rico. PLoS Negl Trop Dis. 2011 Dec;5(12):e1378.

5. WHO. Dengue: guidelines for diagnosis, treatment, prevention and control. http://whqlibdoc.who.int/ publications/2009/9789241547871_eng.pdf. (accessed Sept 26, 2011).

6. Guzman MG, Halstead SB, Artsob H, et al. Dengue: a continuing global threat. Nat Rev Microbiol 2010; 8 (12 suppl): S7-S16.CrossRef | PubMed

7. Beatty ME, Stone A, Fitzsimons DW, et al. Best practices in dengue surveillance: a report from the Asia-Pacific and Americas Dengue Prevention Boards. PLoS Negl Trop Dis 2010; 4: e890. PubMed

8. CDC. Locally acquired dengue-Key West, Florida, 2009-2010. Morb Mortal Wkly Rep 2010; 59: 577581. PubMed
9. Gould E, Gallian P, De Lamballerie X, Charrel R. First cases of autochthonous dengue fever and chikungunya fever in France: from bad dream to reality! Clin Microbiol Infect 2010; 16: 1702-1704. CrossRef | PubMed

10. Amarasinghe A, Letson GW. Dengue in the Middle East: a neglected, emerging disease of importance. Trans R Soc Trop Med Hyg. 2012 Jan;106(1):1-2.

11. Khormi HM, Kumar L, Elzahrany RA. Modeling spatiotemporal risk changes in the incidence of dengue fever in Saudi Arabia: a geographical information system case study. Geospat Health. 2011 Nov;6(1):77-84.

12. Lernout T, Giry C, Binder P, Zumbo B, Durquety E, Lajoinie G, D'Ortenzio E, Filleul L. Emergence of dengue virus serotype 3 on Mayotte Island, Indian Ocean. East Afr J Public Health. 2011 Jun;8(2):155-6.

13. Oki M, Sunahara T, Hashizume M, Yamamoto T. Optimal timing of insecticide fogging to minimize dengue cases: modeling dengue transmission among various seasonalities and transmission intensities. PLoS Negl Trop Dis. 2011 0ct;5(10):e1367.

14. Dharshini S, Vinobaba M, Jude PJ, Karunaratne SH, Surendran SN. Prevalence and insecticide susceptibility of dengue vectors in the district of Batticaloa in eastern Sri Lanka. rop Med Health. 2011 Jun;39(2):47-52.

15. Alphey N, Alphey L, Bonsall MB. A model framework to estimate impact and cost of genetics-based sterile insect methods fordengue vector control. PLOS One. 2011;6(10):e25384. Epub 20110ct5.

16. El-Bahnasawy MM, Khalil HH, Morsy AT, Morsy TA. Threat of dengue fever and dengue haemorrhagic fever to Egypt from travelers. J Egypt Soc Parasitol. 2011 Aug;41(2):289-306.

17. Schmidt WP, Suzuki M, Thiem VD, White RG, Tsuzuki A, Yoshida LM, Yanai $\mathrm{H}$, Haque U, Tho le H, Anh DD, Ariyoshi K. Population density, water supply, and the risk of dengue fever in Vietnam: cohort study and spatial analysis. PLoS Med. 2011 Aug;8(8):e 1001082

18. Aguiar M, Ballesteros S, Kooi BW, Stollenwerk N. The role of seasonality and import in a minimalistic multi- 
strain dengue model capturing differences between primary and secondary infections: complex dynamics and its implications for data analysis. J Theor Biol. 2011 Nov 21;289:181-96.

19. Debarati Guha-Sapir and Barbara Schimmer. Dengue fever: new paradigms for a changing epidemiology. [Cited 2012 March 06]. Available from http://www.eteonline.com/content/2/1/1.

20. Abdallah TM, Ali AA, Karsany MS, Adam I. Epidemiology of dengue infections in Kassala, Eastern Sudan. [Cited 2012 March 03]. Available from http://www.ncbi.nlm.nih.gov/pubmed/22246838.

21. Sanchez L, Maringwa J, Shkedy Z, Castro M, Carbonell $\mathrm{N}$, Stuyft PV. Testing the Effectiveness of CommunityBased Dengue Vector Control Interventions Using Semiparametric Mixed Models. Vector Borne Zoonotic Dis. 2012 Jan 12.

22. Faruque LI, Zaman RU, Alamgir AS, Gurley ES, Haque R, Rahman M, Luby SP. Hospital-based prevalence of malaria and dengue in febrile patients in Bangladesh. Am J Trop Med Hyg. 2012 Jan;86(1):58-64.

23. García C, García L, Espinosa-Carreón L, Ley C. Abundance and distribution of Aedes aegypti (Diptera: Culicidae), and dengue dispersion in Guasave Sinaloa, Mexico. Rev Biol Trop. 2011 Dec;59(4):1609-19.

24. Ali F, Ansari NB, Saleem T, Salahuddin N. Clinical profile and management of dengue fever at a tertiary care hospital in Pakistan. IDJ Jul-Sep 2011; 20 (3)): 3358.

25. Rohani A, Suzilah I, Malinda M, Anuar I, Mohd Mazlan I, Salmah Maszaitun M, Topek 0, Tanrang Y, Ooi SC, Rozilawati H, Lee HL. Aedes larval population dynamics and risk for dengue epidemics in Malaysia. Trop Biomed. 2011 Aug;28(2):237-48.

26. Agarwal R, Kapoor S, Nagar R, Misra A, Tandon R, Mathur A, Misra AK, Srivastava KL, Chaturvedi UC: A clinical study of the patients with dengue hemorrhagic fever during the epidemic of 1996 at Lucknow, India. Southeast Asian J Trop Med Public Health 1999, 30:735-740. PubMed Abstract.

27. Goh KT, Ng SK, Chan YC, Lim SJ, Chua EC: Epidemiological aspects of an outbreak of dengue fever/dengue haemorrhagic fever in Singapore. Southeast Asian J Trop Med Public Health 1987, 18:295-302. PubMed Abstract

28. Ray G, Kumar V, Kapoor AK, Dutta AK, Batra S: Status of antioxidants and other biochemical abnormalities in children with dengue fever. J Trop Pediatr 1999, 45:4-7.

29. Wali JP, Biswas A, Handa R, Aggarwal P, Wig N, Dwivedi SN: Dengue haemorrhagic fever in adults: a prospective study of $\mathbf{1 1 0}$ cases. Trop Doct 1999, 29:27-30.

30. Shekhar KC, Huat OL: Epidemiology of dengue/dengue hemorrhagic fever in Malaysia--a retrospective epidemiological study 1973-1987. Part I: Dengue hemorrhagic fever (DHF). Asia Pac J Public Health 1992, 6:15-25.

31. Ahmad SI, Naeem A, Baqaj HZ, Sheikh SI, Ranja ZA, Satti Al et al. NSI Antigen and Immunogloblin M detection in the acute and early convalescent stages of dengue fever. JRMC ;2010;14(2):56-59.

32. Chareonsook 0, Foy HM, Teeraratkul A, Silarug N: Changing epidemiology of dengue hemorrhagic fever in Thailand. Epidemiol Infect 1999, 122:161-166.

33. Hayes CG, Phillips IA, Callahan JD, Griebenow WF, Hyams KC, Wu SJ, Watts DM: The epidemiology of dengue virus infection among urban, jungle, and rural populations in the Amazon region of Peru. Am J Trop Med Hyg 1996, 55:459-463.

34. Hales S, Weinstein P, Woodward A: Dengue fever epidemics in the South Pacific: driven by El Nino Southern Oscillation. Lancet 1996, 348:1664-1665.

35. Keating J: An investigation into the cyclical incidence of dengue fever. Soc Sci Med 2001, 53:1587-1597.

36. Wasay M, Channa R, Jumanj M, Zafar A. Changing patterns of dengue infection, report from a tertiary care hospital in Pakistan. J pak Med Assoc58; 488;2008.

37. Sanchez L, Vanlerberghe V, Alfonso L, Marquetti MDC, Guzman MG, Bisset J, et al. Aedes aegypti Larval Indices and Risk for Dengue Epidemics. Emerging Infectious Diseases. 2006 May (12): 800-6. 
AUTHOR(S):

1. DR. MUHAMMAD ASIF SHAHZAD

Correspondence Address:

Dr. Muhammad Asif Shahzad

District Officer Health, Faisalabad

2. DR. ABDUL RAUF

District Officer Health Faisalabad

Executive District Officer Health, Faisalabad.

3. DR. HUMAYUN SUQRAT HASAN IMAM

Senior Lecturer, Community Medicine Department

Punjab Medical College, Faisalabad.

4. Miss. Rameesha Humayun

Student 4th year

University Medical and Dental College, Faisalabad

Electronic submission saves time, postage costs and allows the manuscript
to be handled in electronic form throughout the publication process.
Accepts electronic submission of articles via e-mail, attachment in
MS Word format at following address:
info@theprofesional.com
editor@theprofesional.com
publication@theprofesional.com
for more details, visit us ;
www.theprofesional.com

